\title{
Classifying the Diversity of Urban Diversities: an Inductive Analysis of European Cities
}

\author{
Asya Pisarevskaya ${ }^{1}$ (D) Peter Scholten ${ }^{1} \cdot$ Zeynep Kaşlı ${ }^{2}$
}

Accepted: 24 May 2021/Published online: 2 July 2021

(C) The Author(s) 2021

\begin{abstract}
This paper provides an empirical classification of migration-related diversities in 166 European cities. The local turn in migration studies has shown that migration-related diversity may take varied forms in different cities. Our understanding of how and why cities differ is lagging behind the wealth of existing conceptualisations. This is partly because most studies look only at one kind of city, in particular, superdiverse global cities. This paper takes a systematic inductive approach to map the diversity of migration-related diversities in urban setting and understand the reasons behind such variations. Applying quantitative classification methods to European cities in France, Germany, the Netherlands and Italy, we search for a new meaningful classification of the urban diversity configurations based on measures of volume, variety and spread of migration-related diversity. Five empirical clusters of cities of migration are found: superdiverse cities, migrant minority cities, new diversity cities, low-migration cities and non-diverse cities. Subsequently, we develop a better qualitative understanding of these clusters by examining typical cities, their economic positioning, migration history, their policy and political structures, as well as their social and geographical position. A thorough classification, we argue, is necessary to have a more differentiated view of the existing urban diversities and go beyond one-size-fits-all solutions for urban governance of migration-related diversity.
\end{abstract}

Keywords Classification · Migration-related diversity $\cdot$ Local level $\cdot$ Cities $\cdot$ Superdiversity - Segregation · Urban

Asya Pisarevskaya

pisarevskaya@essb.eur.nl

1 Department of Public Administration and Sociology, Erasmus School of Social and Behavioral Sciences, Erasmus University Rotterdam, Rotterdam, the Netherlands

2 International Institute of Social Studies, Erasmus University Rotterdam, Rotterdam, the Netherlands 


\section{Introduction}

The 'local turn' in migration studies has shifted attention on migration-related diversity to the urban level of analysis (Zapata-Barrero et al., 2017). It is widely accepted that contemporary urban landscapes are increasingly shaped by migrants across the globe while the worldwide trend of decentralisation makes cities important players for the governance of migration and migration-related diversities (Çağlar \& Glick-Schiller, 2018; Lacroix \& Desille, 2018). Scholars have previously examined migration-related urban diversity in many ways. They studied peculiar 'majority-minority cities' where more than half of the population has a migration background (Crul, 2016), unveiled the multidimensional diversity amongst migrants (Vertovec, 2007), analysed urban segregation and unease with increasing diversity (Mepschen, 2019) and highlighted the social, economic and cultural incorporation of migrants (Glick Schiller \& Çağlar, 2009). Scholars focusing on the political aspects wrote on migrants' political participation (De Graauw \& Vermeulen, 2016) and illustrated differences in local integration and diversity policies (Martínez-Ariño et al., 2019; Schiller, 2016) as well as the power of the urban level vis-à-vis national and regional levels of governance (Dekker et al., 2015; Emilsson, 2015; Zapata-Barrero et al., 2017).

However, scholarly attention to the migration-related diversity configurations in urban contexts has been rather uneven. There is extensive literature particularly on diversity in global cities or major cities, which results from their central position in international economic exchanges and migration history (Foner et al., 2014; Glick Schiller \& Çağlar, 2009; Sassen, 2001). Yet, such global cities represent only a minor part of all cities experiencing migration and diversity. Next to cities like Amsterdam or Milan with varieties of ethnicities or countries of origin, there are many others, like Marseille and Naples, where a limited number of nationalities reside. The same goes for border towns, like Trier, where diversity is characterised by passing through or commuting migrant populations. There is a growing strand of literature focusing on a broader range of cities and rural areas (Baumgärtel et al., 2019; Caponio \& Borkert, 2010; Glick Schiller \& Çağlar, 2009; Glorius, 2017; Martínez-Ariño et al., 2019; van Breugel, 2020). Our systematic analysis is built on these previous efforts, which offer rather small scale and in-depth qualitative comparisons of several cases. Our study aims to contribute to empirical and theoretical understandings of the differences of migration-related diversity configurations in cities.

We develop an inductive classification of urban diversities based on an analysis of 166 cities in four European countries based on some characteristics, namely volume and variety of residents' countries of origin and the spatial concentration of the newcomers and established residents. Our analysis offers a systematic approach to the study of the broad variety of cities positioned between the extremities of migrationrelated diversity observed in so-called global cities and non-diverse small towns. What are those in-between configurations of diversity amid the superdiverse and non-diverse dichotomy? Which cities are located in the midst of that hypothetical continuum? In this paper, we answer these questions, intending to shift the attention of future research to those understudied configurations of migration-related diversity. Given the limitations of available cross-country comparative data, we develop a simple yet functional approach to mapping the cities of different countries along three dimensions of migration-related urban diversity: volume, variety and spread of new migrants in the 
city. With its comparative approach and focus on first generation of migrants, this paper attempts to remedy at least some aspects of the double trap of methodological localism and methodological nationalism (Brenner, 2011; Glick Schiller \& Çağlar, 2009), namely the tendency to view spaces of migration, be they cities, regions or nationstates, as static frames within which social relations take place instead of taking them as spaces coproduced through the very social relations under investigation (Brenner, 2011: p. 37).

In other words, building on existing comparative studies and the local turn in migration studies, we offer a crucial next step towards a classification of migrationrelated urban diversities. After introducing the concept of migration-related urban diversity, we first inductively group cities similar in terms of volume, variety and spread of diversity by using a k-median cluster analysis. Next, we zoom in on a number of typical cities per each cluster, in order to understand whether the clustering may indicate further contextual interdependencies of economies and migration-histories of cities. Finally, the potential of these empirical clusters is evaluated in light of their contribution to theory-building, and further avenues for research are proposed.

\section{From Comparative Studies to Classification of Migration-Related Urban Diversity}

Numerous comparative studies have contributed to our understanding of locality beyond the paradigmatic global cities. For instance, inquiries on European cities have comparatively addressed the issues of housing and de/segregation (Arbaci \& Malheiros, 2010; Musterd \& van Kempen, 2009), social inclusion/exclusion in European metropolises (Body-Gendrot \& Mariniello, 2000) and local reception of migrants and asylum seekers in cities of different scales (Bauder \& Gonzalez, 2018; Baumgärtel et al., 2019; Glorius, 2017; Ikizoglu-Erensu \& Kaşl1, 2016). From a governance perspective, there are comparisons of multiple cities in terms of their local integration and diversity policies (Caponio \& Borkert, 2010; Dekker et al., 2015; Emilsson, 2015; Schiller, 2016) and politics (de Graauw \& Vermeulen, 2016). Yet such in-depth comparative studies shed light on key differences and underlying contextual factors only across a few localities.

Recent studies included a systematic analysis of a larger number of cases, for instance, Martínez-Ariño et al's (2019) comparison of the twenty largest cities of France and Germany to identify city-level diversity policy instruments and van Breugel's (2020) study of 16 Dutch cities of different sizes examining the panorama of urban diversity policy approaches in a relational perspective. These are welcome attempts aiming to overcome at least one of the conceptual barriers stemming from methodological nationalism that Glick Schiller and Çağlar (2009, p. 181) identified, restricting global perspective on locality to global cities and treating them as paradigmatic cities of their respective national contexts. Yet those studies have a rather selective focus on the different configurations of urban diversity policies.

Glick Schiller and Çağlar's (2009) work, 'comparative theory of locality', has certainly paved the way for a new way of thinking about the impact of migration in cities by bringing urban and migration studies into a dialogue. Glick Schiller and Çağlar explicitly state that their scalar approach represents a range of "positions... 
within a dynamic continuum of power, which they [cities] achieve and within which they must constantly reposition themselves $(2009$, p. 190), pointing at the changing nature of both power and demographics of localities. Their four-scale continuum captures the different degrees of the 'neoliberal economic restructuring' in cities, which could vary from the most globally prominent (top-scale and up-scale) to the least globally prominent (low-scale and down-scale). Their model shows not only how cities may offer very different incorporation pathways for migrants primarily depending on the (re)positioning of the cities in that global neoliberal restructuring process indicated by their economic, political and cultural power. More importantly, their approach allows looking beyond 'global cities', as it considers factors other than the geographical scale or population size of a city to measure the relative positioning of the cities.

Clearly, Glick Schiller and Çağlar's classification does not intend to take stock of the existing urban diversity manifestations per se. Nevertheless, their spectrum of the economic incorporation opportunities is useful in search for explanations for different migration-related diversity configurations identified by the cluster analysis presented in this study.

\section{Urban Configurations of Diversity: Volume, Variety and Spread}

What do we mean by migration-related diversity? The debate on the diversity of the urban population is stimulated especially among migration scholars in Europe by Vertovec's, 2007 ERS article where he coined the term superdiversity as a 'summary term' based on his depiction of the population diversity in London and in the UK with reference to net inflows, countries of origin, languages, religions, migration channels and immigration statuses, gender, age, space/place and practices of transnationalism (for a summary of the origin and application of the term by other scholars, see Meissner \& Vertovec, 2015).

While the dynamics and results of migration-related diversity in the city have been studied from different angles, the operationalisation of superdiversity has triggered methodological debates ever since (e.g. Connor 2014). Our systematic literature review shows that while it is widely accepted that migration-related diversity is multidimensional and that a population with a migration background has diverse attributes and experiences beyond their ethnic, racial or country of origin differences, ethnic or racial diversity is still the starting point of almost a third of studies that examine migrationrelated diversity in urban context. Only a handful of studies make the effort to capture the complexity of a population's diversity by incorporating more than one aspect of demographic diversity. ${ }^{1}$

One obvious reason is a lack of availability of comparable data at the city level on many of the aforementioned dimensions of superdiversity and even for global cities. More importantly, there is no agreed definition of who the migrant is in the superdiversity debates. The various intersecting aspects included in the research of migration-related urban diversity lead to more opaque definitions of the 'migrant' and

\footnotetext{
${ }^{1}$ At the time of writing, our manuscript titled 'Towards a multi-dimensional approach to migration-related diversity: A systematic review of the literature on urban diversity research' is under review but can be available upon request.
} 
'migration-related diversity', since many studies and official records count even the descendants of people with migration background as migrants (Bowen \& Kalir, 2014). While being aware of our inability to overcome the ethnic lens completely - which is a key conceptual barrier stemming from methodological nationalism - we try to avoid essentialising categorisations by using a narrow definition of 'migrant' as the first generation of migrants.

In order to capture the multidimensional nature of migration-related diversity, while taking into account the conceptual (and ethic) problems of conceptualising migrants, we will focus on a number of basic dimensions of migration-related diversity that seem to have the widest agreement in the literature. The notions of volume, variety and spread are adopted in this urban-level comparative analysis, meaning that we look at the volume of newcomers, the variety of their nationalities or countries of origin and the spatial concentration of newcomers versus established residents.

The first dimension of migration-related diversity involves the volume of diversity, or the migrant population as a share of the total population. The volume of diversity is considered important because it has implications for 'fading majority cultures' (van Oudenhoven \& Ward, 2013), influences attitudes of non-migrant populations towards migration (Weber, 2015) and has sense of belonging (Wise, 2011); it also plays a role in local-level policy developments (Martínez-Ariño et al., 2019, p. 663). While cities with few migrants are referred to as non-diverse, or ethnically homogeneous (Glorius, 2017; Leitner, 2012), the extremity of this dimension of diversity has been theorised by Crul (2016) as 'majority-minority cities', which describes localities where the (second generation) migrant population is outnumbering the non-migrant population.

Besides this traditional way to understand the degree of migration-related diversity, a consensus seems to have emerged in migration studies that it is not only the relative size of the migrant population, but also the variety of diversity within this population (Grzymala-Kazlowska \& Phillimore, 2018) that matters. This is what we consider a second relevant dimension. The concept of 'superdiversity' (Vertovec, 2007) has invited migration scholars to pay attention not only to a great multitude of origins, but also of languages, religions, legal statuses, lifestyles, migration channels, incorporation trajectories and other aspects. The variety of diversity is important to consider because it has implications for conviviality in urban settings (Wessendorf, 2016), for provision of social services to extremely diverse populations (Phillimore, 2015), as well as for innovation, creativity (Hahn, 2010) and cultural pluralism (Salzbrunn, 2014).

A third aspect of urban diversities extensively discussed in the literature is segregation (García \& Moreno, 2011; Musterd \& van Kempen, 2009). Segregation reflects a spatial dimension of urban settlement that captures the geographical spread of migration-related diversity. Segregated cities are those in which migrants and non-migrants commonly live in distinct areas, including socially deprived areas referred to as ghettoes (Grzegorczyk, 2012) or gated communities of wealthy residents (Borsdorf et al., 2016). Non-segregated cities are those in which neighbourhoods are usually mixed both in terms of migration background, race, ethnicity and social class. The pattern of migrants' residence across the cities can be a result of long-term, structural dynamics of urban settlement (Bolt et al., 2010), such as availability of housing and its cost, and could point to existing class inequalities (Ferreira, 2010; Massey \& Denton, 
2018) and municipal regulations related to gentrification and social-mixing, as well as integration policies (van Gent \& Musterd, 2016).

\section{Methodology and Description of Data}

The central research question in this paper is what clusters of urban diversities can be identified and how such different clusters can be explained. To reach beyond current sporadic comparative studies on urban diversities, we aim to analyse the configurations of urban diversity by means of empirical classification (Bailey, 1994). Classifications capture the essential similarities and differences of various manifestations of an observed phenomenon and allow us to understand it on a more abstract level (Collier et al., 2008). Being both a result of and a tool for assessments of similarity and difference (Ward, 2010), they can be performed in various ways.

On the one hand, there are classical approaches to classifications, which are theory-driven and often qualitative, and are called typologies. On the other hand, there are empirically driven taxonomies, represented by quantitative classification techniques, such as cluster analyses (Bailey, 1994). Typologies represent a system of Weberian ideal types based on hypothetical extremes that cannot be observed empirically, or constructed types based on most commonly shared characteristics (McKinney 1966, as cited in Bailey, 1994). On the contrary, a quantitative classification (or taxonomy) provides inductive categorisation of empirical situations, based on the measurement of similarities across a number of variables (Bailey, 1994). Either theoretically constructed or inductively derived categories should be mutually exclusive and collectively exhaustive, thus grasping all possibly existing manifestations of a concept also beyond the observed cases under analysis (Bailey, 1994; Collier et al., 2008, p. 158).

In this study, our goal is to perform a quantitative classification of a large number of urban diversities in selected countries as a first attempt to give an empirical proof to an implicit assumption that diversities are configured differently in non-global cities. By following three basic dimensions of urban diversities, volume of diversity, variety of diversity and spread of diversity, we strive to demonstrate in which cities and in what way these dimensions coincide. While we chose the relevant diversity dimensions based on previous literature, our approach is inductive in the first place and attempts to give insight into the diversity of urban diversities which may go unnoticed in a deductive or top-down typologising attempt.

It is expected that our cluster analysis based on the three dimensions of urban diversity (volume of diversity, variety of diversity, segregation) will reveal several clusters of cities that share distinctive configurations of migration-related diversity. We clustered 166 European cities using Stata 14 software. Such a large-N classification analysis provides a unique empirical mapping of urban diversities. Subsequently, several cities typical of the identified clusters were examined to get a better understanding of urban characteristics within each of the specific configurations of diversity. 


\section{Datasets and Operationalisation}

The cluster analysis was performed on 166 cities from four ${ }^{2}$ countries: the Netherlands $(\mathrm{N}=10)$, Germany $(\mathrm{N}=95)$, France $(\mathrm{N}=35)$ and Italy $(\mathrm{N}=26)$. The dataset was constructed from two distinct ones: D4I (Alessandrini et al., 2017) and MarketLine City Analysis database (MarketLine, 2019). Only the cities present in both datasets were included in the analysis. It is important to note that these are not all 301 existing functional urban areas (FUA) in these four countries (OECD, 2012), but 55\% of the total number. One hundred thirty-five functional urban areas were not part of this analysis due to the unavailability of data. Since this analysis is an inductive attempt to develop a meaningful classification of urban diversity, our sample should be sufficient for this purpose.

From the D4I database of the European Knowledge Centre for Migration and Demography (Alessandrini et al., 2017), we obtained information on the share of migrants, total population and number of origins in each city. D4I contains harmonised and spatially disaggregated data from 2011 from national statistics agencies in several European countries (either census or registry-based data). ${ }^{3}$ The harmonised data consisted of a uniform spatial grid of $100 \times 100 \mathrm{~m}$ with an estimated number of residents per origin residing in each 'cell'. For an urban-level analysis, this spatial grid was aggregated into larger units. Due to cross-country comparability issues, ${ }^{4}$ our best choice was to use FUA as a definition of a city, that is 'an economic unit characterised by densely inhabited 'urban cores' and 'hinterlands' whose labour market is highly integrated with the cores' (OECD, 2012).

Based on the available data, we measured the volume of diversity as either the share of foreign-born, or the share of foreign nationals among the total population residing in FUA. This means that we work only with data on so-called first-generation migrants. It should be noted that this measure can differ from the self-identification or bureaucratic categorisations of migrants, which in many countries include the second or even the third generation and beyond. Not only are there structural differences in data on the second generation between the countries, which would impede a systematic comparison, we also believe that anyone beyond the 'first generation' should not be referred to as migrants.

Since the census methods across European countries are different, even with the harmonisation efforts of KCMD (Alessandrini et al., 2017), there is an inevitable limitation in our data on the first generation of migrants: that is, whereas some countries collect data on foreign nationals (FR and IT), others have data on the foreign-born population (DE and NL). However, we see the two as comparable because the data on foreign nationals only includes those that do not have the nationality of the country in

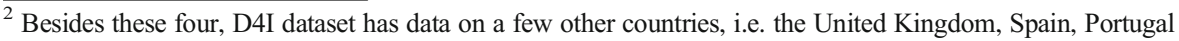
and Ireland. We could not include them in our analysis because in these countries not all migrant origins were recorded but only the most common ones. Due to that discrepancy their data was not comparable with DE, FR, NL and IT.

${ }^{3}$ The initially gathered data was composed by different spatial units: postcodes (the Netherlands), 100 by 100 $\mathrm{m}$ grids (Germany) and census tracts in the rest of the countries. And was processed and harmonised by the KCMD to make the data comparable.

${ }^{4}$ The smaller units of analysis, such as local administrative units (LAU), differed significantly across the countries, resulting that some big cities, such as Paris, appears in the data set as several LAUs. That would have prevented us from comparing, for instance, Berlin and Paris.
} 
which they are residing (so it does not include multiple nationalities). Additionally, the purpose of this study is not to come up with the ultimate and unquestionable classification of cities, but rather to demonstrate the existing diversity among urban diversities and analyse the possible reasons for those groupings. We agree that once a more homogeneous mode of data collection is adopted in Europe, the classification of cities could be different, and equally, that such classification may change with time.

The variety of diversity was operationalised as the number of different countries of origin or nationalities represented in the urban population. ${ }^{5} \mathrm{~A}$ higher variety means a higher number of different countries from which migrants originate. Of course, in order to exploit concept of superdiversity to the fullest, we would have to also look at other parameters (legal status, religion, language and social status, etc.) revealing how superdiverse the population of migrants is, but we do not have comparable data on that. Having to use only migrant origins as an indicator of variety of diversity, we assume that this would be correlated with higher diversification of languages and religions, as some studies indicate (Connor 2014).

Finally, the spread of diversity was measured by an index of dissimilarity (also called index of segregation) between the two groups 'migrants' and 'non-migrants'. It was calculated on the grids-based original KCMD dataset. The index was calculated as follows:

$$
I S_{x y}=\frac{1}{2} \sum_{i=1}^{k}\left|x_{i}-y_{i}\right|
$$

where $\mathrm{X}_{\mathrm{i}}$ is the number of city residents of native origin in a grid $i$, divided by the total number of non-migrants in the whole city. $\mathrm{Y}_{\mathrm{i}}$ is the number of migrant residents in a grid $i$ divided by the total number of migrants in the whole FUA. $K$ is the number of grids that make up the FUA. The absolute values of the difference between $X_{i}$ and $Y_{i}$ (without signs - or + ) for each grid are summed and divided by 2 (Table 1 ).

\section{Quantitative and Qualitative Analysis of Cities per Cluster}

Subsequently, a combined quantitative and qualitative analysis of typical cities per cluster was performed. We defined typical cities by identifying median cities in each cluster and then selected three cities from at least two different countries. We collected more quantitative data on those cities. Based on previous literature (Glick-Schiller and others), we assumed that the configuration of urban diversity might at least partially be shaped by the economic characteristics of the cities. From MarketLine City Analysis database (MarketLine, 2019), we obtained additional information about cities' economies in the period of 5 years prior to and including 2011, since the population data from D4I dataset is from that year. GDP and household income combined with levels of unemployment approximate the overall prosperity of the city's population and its importance in the global and national economy, while the share of the population employed in certain sectors indicates the kind of jobs that are available in the city for both migrants and non-migrants alike (Table 2).

\footnotetext{
${ }_{5}^{5}$ For privacy reasons, our data does not reveal countries of origin where there are fewer than 5 persons in the city.
} 
Table 1 Operationalisation and sources of key concepts

\begin{tabular}{lcr}
\hline Concept & Operationalisation & Sources \\
\hline $\begin{array}{l}\text { Volume of diversity } \\
\text { (share of migrants })\end{array}$ & $\begin{array}{c}\text { Percentage of urban population that was born in another country or has } \\
\text { another nationality }\end{array}$ & D4I, \\
$\begin{array}{l}\text { Variety of diversity } \\
\text { (number of origins) }\end{array}$ & $\begin{array}{c}\text { Total number of different countries in which at least 5 persons from a } \\
\text { city were born, or have a nationality of }\end{array}$ & D4I, \\
$\begin{array}{l}\text { Spread of diversity } \\
\text { (segregation) }\end{array}$ & Index of dissimilarity between 'migrants' and 'non-migrants' & 2011 \\
City size & Total population residing in Functional Urban Area & D4I, \\
& & D4I, \\
\hline
\end{tabular}

Besides looking at quantitative information on economic variables, we also did a qualitative analysis of the selected cities per cluster. This was based on a review of secondary sources on these cities, collecting information on the migration history of a city, policy and political structures in a city, social background of a city (working class or post-industrial city, service city, etc.) and geographical position of a city (border city, port city, etc.).

\section{Description of Quantitative Data}

The analysed cities in Germany, the Netherlands, Italy and France on average host populations of 75 different origins, which amount to $11 \%$ of the first-generation migrants (Table 3). The total population mean reaches 647.7 thousand residents, though the large majority of the urban areas under analysis are around 200 thousand residents. Mean GDP per capita in this data set between the years 2006 and 2011 was around 40 thousand EUR, and the average income was around 50 thousand EUR per household. The mean unemployment rate in these urban areas was around $8 \%$. Of course, it should also be mentioned that, in that period, European economies were undermined by the 2008 economic crisis. Nevertheless, these estimates are reliable because both pre-crisis and post-crisis years are included in the calculation.

Table 2 Operationalisation and sources of key concepts for the quantitative analysis per cluster

\begin{tabular}{|c|c|c|c|}
\hline Concept & Indicator & Operationalisation & Sources \\
\hline $\begin{array}{l}\text { Economic } \\
\text { power }\end{array}$ & GDP & $\begin{array}{l}\text { Mean GDP per capita in Purchasing Power Parities } \\
\text { (PPP), for the period 2006-2011 }\end{array}$ & MarketLine \\
\hline $\begin{array}{l}\text { Household } \\
\text { wealth }\end{array}$ & Mean household Income & $\begin{array}{l}\text { Mean household income in PPPs for the period } \\
\text { 2006-2011 }\end{array}$ & MarketLine \\
\hline Unemployment & Unemployed, \% & $\begin{array}{l}\text { Mean share of unemployed for the period } \\
\text { 2006-2011 }\end{array}$ & MarketLine \\
\hline $\begin{array}{l}\text { Focus of urban } \\
\text { economy }\end{array}$ & $\begin{array}{l}\text { Employed in agriculture, } \\
\% \\
\text { Employed in Industry, \% } \\
\text { Employed in Services, \% }\end{array}$ & $\begin{array}{l}\text { Mean share of employed in this sector in the period } \\
2006-2011\end{array}$ & MarketLine \\
\hline
\end{tabular}


Table 3 Descriptive statistics of the analysed dataset, functional urban areas, $\mathrm{N}=166$

\begin{tabular}{lllll}
\hline Variables & Mean & Std. dev. & Min & Max \\
\hline $\begin{array}{l}\text { Population variables, } 2011 \\
\text { Number of origins }\end{array}$ & 75.60 & 28.71 & 17.00 & 162.00 \\
Share of migrants & 0.11 & 0.05 & 0.01 & 0.22 \\
Total population & $647,700.90$ & $1,019,077.00$ & $87,827.00$ & $9,446,721.00$ \\
Economic variables (means of years 2006-2011) & & & \\
GDP p capita, in PPP & $40,319.07$ & $14,458.46$ & $20,854.22$ & $125,483.60$ \\
Mean household income & $51,198.04$ & $18,232.95$ & $22,653.86$ & $169,186.90$ \\
Unemployed, \% & 8.10 & 3.17 & 2.94 & 17.57 \\
Employed in sectors, \%: & & & & \\
Agriculture & 2.12 & 1.49 & 0.11 & 10.12 \\
Industry & 24.98 & 6.87 & 8.38 & 44.65 \\
Services & 72.88 & 6.97 & 54.75 & 90.57 \\
\hline
\end{tabular}

Regarding the sectors of employment, the reader can see that most of the population is employed in services, less in industry and even less in agriculture. This is not surprising, since these cities are located in post-industrial countries. Therefore, it needs to be mentioned that conclusions that we draw based on this data may not be immediately applicable to the cities with primarily an industrial or agricultural economy.

\section{Identifying Clusters of Urban Diversities}

As a first step in this research, we tried to identify empirical clusters of cities that share a similar configuration of diversity. We implemented the cluster analysis (K-medians) based on the number of origins, share of migrants and level of segregation per city. Following the inductive approach, we let the data reveal the most optimal number of clusters, rather than imposing our own. Following the methodology described in Makles (2012), we conducted 30 trials with random seed points to estimate the within sum of squares (WSS), WSS (log), Eta-squared and PRE statistics. By identifying the 'elbow' in the graphs, we found that most of these trials indicated that five was the optimal number of groups. Appendix reveals that with five clusters or more, the WWS is stable below 200, meaning that cities within clusters are most similar to each other in terms of the three variables. PRE shows that the improvement of similarity within clusters is very marginal if the number of clusters is more than 5. This supports working with a 5-group clustering because such partition is accurate enough and captures the nuances of data, while keeping the number of groups manageable.

Therefore, our cluster analysis leads to the definition of 5 clusters of cities (see Figs. 1 and 2). We develop, analyse and subsequently label these clusters in the following sections. Table 4 summarises the medians of these five clusters on the three indicators of this analysis: number of origins, migrant share and segregation. Our clusters are empirically formed and define groups of cities that share the most similar values in 


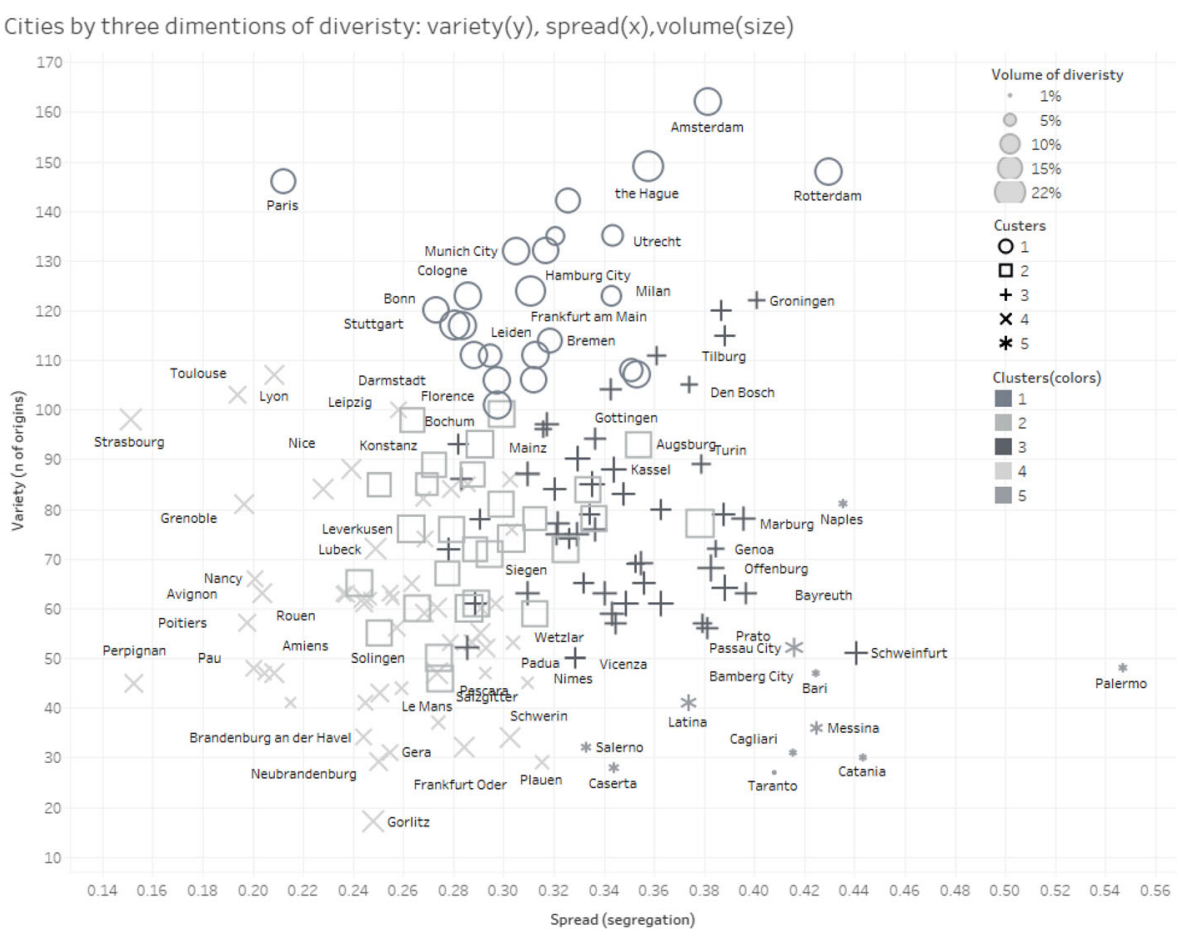

Fig. 1 Cities clustered by variety (origins), volume (share of migrants) and spread of diversity (segregation index)

terms of the three core dimensions of diversity. After the qualitative analysis of the identified clusters, we would be able to understand more clearly what kinds of cities are grouped together and therefore could more confidently assign labels to these groups.

We can see that cities of Germany, Italy and France are found in 4 or 5 different clusters, revealing a variety of urban diversity configurations also within the countries (Fig. 3). In the Netherlands, the cities are found in two clusters (1 and 3), which are both characterised by high variety of diversity. This observation proves that, within each given country, there is more diversity in urban diversities besides the well-known distinction of the two extremities: superdiverse global cities and non-diverse towns.

In terms of countries, the cities under analysis are not evenly distributed across clusters. Some countries are overrepresented in some clusters, for instance, Italian cities constitute $90 \%$ of all cities in cluster 5 . German cities represent $96 \%$ within cluster 2. Looking at the distribution from the countries' perspective, it is clear that the majority of French cities (89\%) belong to cluster 4, and the Dutch cities are split between two clusters 1 and 3 . Italy and Germany reveal more varied urban diversity configurations. Of course, an even distribution of countries across the clusters should not be expected, as country-level characteristics inevitably shape diversity at urban level. The geographical location of countries (i.e. at the EU southern border), history, colonial ties or their absence, the history of bi-lateral labour migration agreements between receiving and sending countries determines the differences of migrant origins among the countries. Besides, various policy factors can be at work shaping urban diversity differently in different countries. For instance, in Germany, the higher adoption of diversity policies 


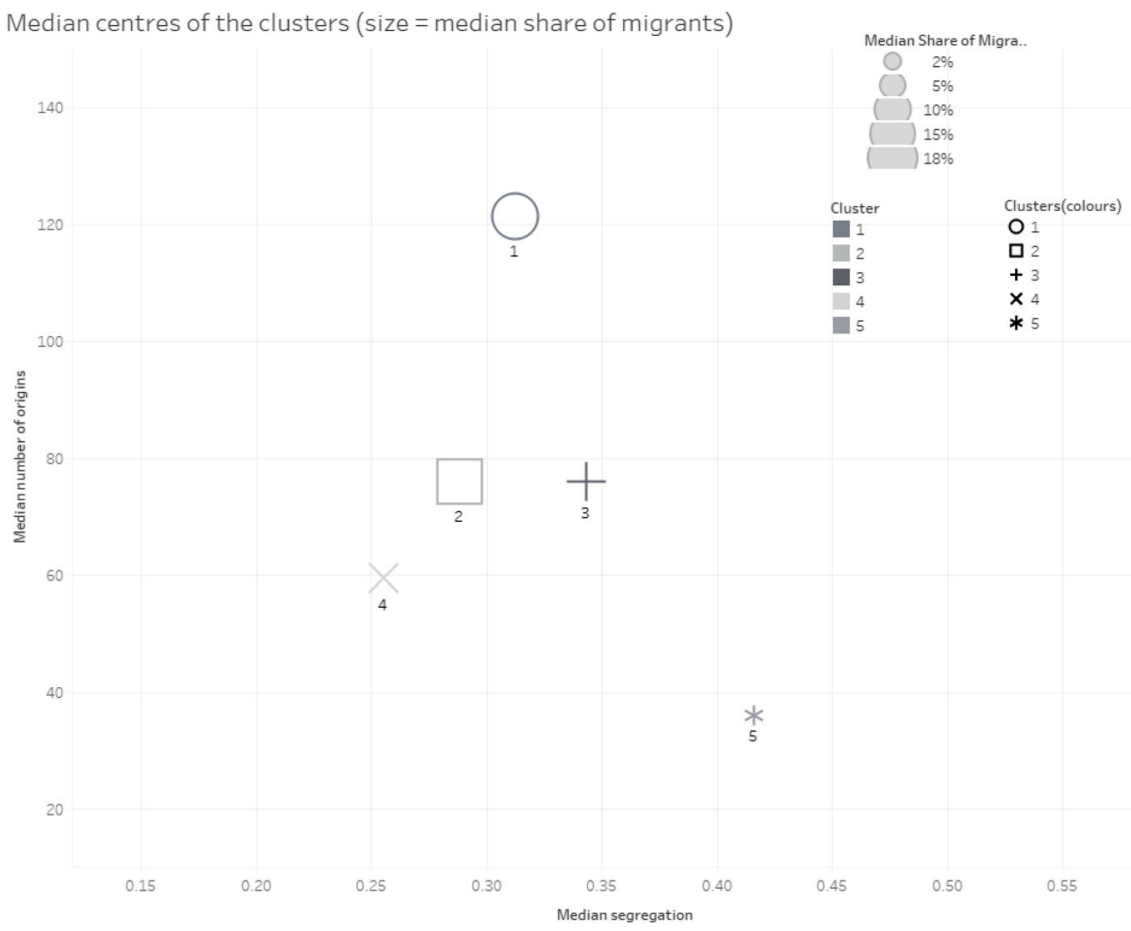

Fig. 2 Simplified mapping of clusters

seems to be associated with higher diversity rates in cities, while in France, political composition of local governments seems to be a stronger factor of diversity levels (Martínez-Ariño et al., 2019). Similarly, differences in countries' governance approaches of migration and integration, as well as distinct economic opportunities in the analysed timeframe, condition the resulting urban manifestations of diversity. While we acknowledge the country-level differences between cities, the main goal of this article is to demonstrate the patterns of urban diversity configurations that transcend national boundaries; thus, the focus in subsequent sections will be on comparison of clusters.

Table 4 Summary table-median centres of these 5 clusters

\begin{tabular}{lllll}
\hline Clusters & Diversification & Migrant share & Segregation & N of cities \\
\hline 1 & 121.5 & $16 \%$ & 0.31 & 24 \\
2 & 76 & $18 \%$ & 0.29 & 28 \\
3 & 76 & $11 \%$ & 0.34 & 49 \\
4 & 59.5 & $7 \%$ & 0.26 & 54 \\
5 & 36 & $2 \%$ & 0.42 & 11 \\
Medians & 72 & $11 \%$ & 0.30 & - \\
\hline
\end{tabular}




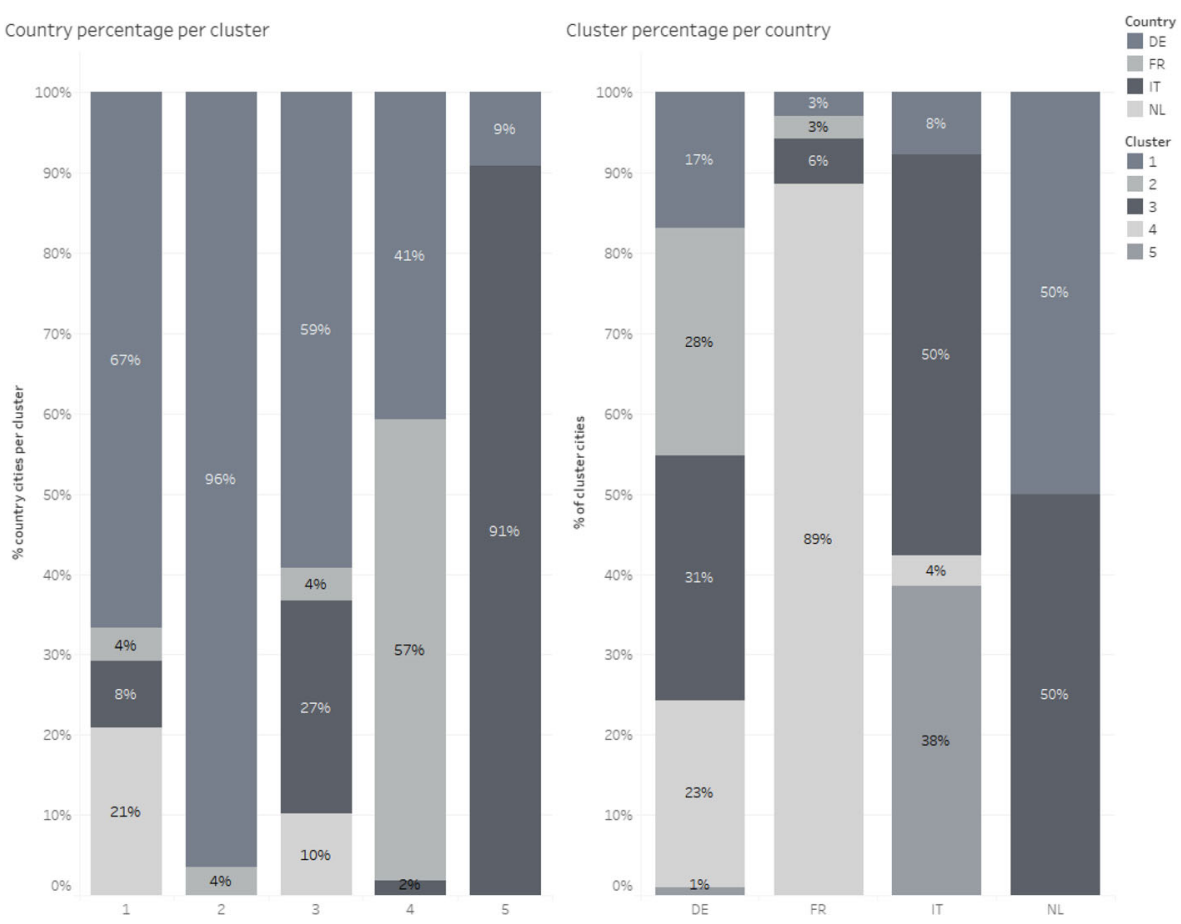

Fig. 3 Country distribution

\section{Understanding the Clusters of Urban Diversities}

In the second step of our analysis, we examined what types of cities are represented in each cluster. What do the clusters actually mean and how can we explain that some cities share a specific configuration of diversity? To do so, we have first taken stock of several key variables for the cities, including city size and various economic indicators on cities (see Table 5). This shows significant variation between the clusters, both in terms of size and economic position.

Subsequently, we identified median cities within each cluster for a closer qualitative analysis (see Table 6). We expect median cities to be the most representative for a city cluster. For every cluster, as much as possible, we chose median cities from at least two different countries. Subsequently, we zoomed in on each of the clusters, trying to get a better understanding of what binds cities in a cluster and what could explain the various clusters.

\section{Cluster 1: Mixed Cities with Many Migrants from Many Backgrounds (Superdiverse Cities)}

The first cluster represents relatively large and highly diverse cities. This is manifested in an average of over 121 different nationalities per city, and an average first-generation migrant share of $16 \%$. Furthermore, this cluster includes large functional urban areas with an average total population of 1.3 million. The cities have an above-average GDP and household income and low levels of unemployment, therefore indicating a strong 
Table 5 Average economic variables for the city clusters

\begin{tabular}{|c|c|c|c|c|c|c|c|}
\hline \multirow[t]{2}{*}{ Cluster } & \multirow{2}{*}{$\begin{array}{l}\text { Average total } \\
\text { population }\end{array}$} & \multirow{2}{*}{$\begin{array}{l}\text { GPD per } \\
\text { capita, PPP }\end{array}$} & \multirow{2}{*}{$\begin{array}{l}\text { Mean household } \\
\text { income, PPP }\end{array}$} & \multirow{2}{*}{$\begin{array}{l}\text { Unemployment, } \\
\%\end{array}$} & \multicolumn{3}{|c|}{ Employed in sectors, \% } \\
\hline & & & & & Agriculture & Industry & Services \\
\hline 1 & $1,333,204.00$ & $50,597.25$ & $59,795.85$ & 5.84 & 0.83 & 17.82 & 81.68 \\
\hline 2 & $270,370.00$ & $38,853.15$ & $49,906.16$ & 7.62 & 0.77 & 28.11 & 69.68 \\
\hline 3 & $407,993.00$ & $40,615.30$ & $52,084.89$ & 6.24 & 2.07 & 27.05 & 71.25 \\
\hline 4 & $202,943.50$ & $31,036.30$ & $40,373.35$ & 9.44 & 2.37 & 22.08 & 74.46 \\
\hline 5 & $483,668.00$ & $24,240.29$ & $31,485.72$ & 12.34 & 4.17 & 20.35 & 74.97 \\
\hline
\end{tabular}

economic profile, with a vast majority of population employed in the service sector. They carry strong resemblances to what Glick Schiller \& Çağlar, 2009) have described as top-scale cities at the winning end of the post-industrial neoliberal economic restructuring. Capital cities, such as Amsterdam, the Hague, Rome, Paris and Berlin, are part of this cluster, as well as other regional capitals-Dusseldorf, Frankfurt am Main, Munich, Bonn, Bremen and big centres of commerce, i.e. Rotterdam, Hamburg, Milan and Hannover. However, some smaller student cities also belong to this cluster: Leiden, Utrecht, Freiburg and Heidelberg.

When looking more closely at median cities like Cologne, Munich and Rotterdam, it becomes clear how deeply entwined the city's economies are with migration. The strongly internationalised economies of each of these cities have relied heavily on mobility, for instance for the manufacturing industries in Munich and the port of Rotterdam. With the development of these cities, this has increasingly also brought immigration of high-educated people, such as for the high-tech in Munich. All three cities can be qualified as post-industrial cities with an increasing dependence on service economies. However, migration-related diversities in these cities extend far beyond the presence of foreign-born or first-generation migrants. When taking into account the descendants of migrants, even more than half of the population of Rotterdam has a migration background. A city like Munich also reveals how the diversity of the city is an accumulation of its migratory past, for instance with descendants of guest labourers (from Turkey in particular), from the refugees from former Yugoslavia (in particular

Table 6 Selected median cities per cluster

\begin{tabular}{ll}
\hline Cluster descriptions & Selected cities \\
\hline $\begin{array}{l}\text { 1. Mixed cities with many migrants from many } \\
\text { backgrounds }\end{array}$ & $\begin{array}{c}\text { Cologne (GER), Munich (GER), Rotterdam } \\
\text { (NL) }\end{array}$ \\
$\begin{array}{l}\text { 2. Mixed cities with many migrants from few backgrounds } \\
\text { Paderborn (GER), Giessen (GER), Mulhouse } \\
\text { (FRA) }\end{array}$ \\
$\begin{array}{l}\text { 3. Segregated cities with few migrants from many } \\
\text { backgrounds }\end{array}$ \\
$\begin{array}{l}\text { 4. Mixed cities with low diversity } \\
\text { 5. Segregated non-diverse cities }\end{array}$ \\
$\begin{array}{l}\text { Metz (FRA), Anger (FRA), Weimar (GER) } \\
\text { Messina (ITA), Passau (GER), Bari (ITA) }\end{array}$ \\
\hline
\end{tabular}


Croats), more recent refugees (in particular Syrians) and many high-skilled migrants from the USA, China and India.

There are some differences within this cluster, for instance, in terms of the types of migrant groups present in these very diverse cities. The diversity of the urban population in Cologne and Rotterdam mainly results from low-skilled migrant labour coming to the cities, for instance in the form of the guest labourers for the industries of Cologne and the harbour of Rotterdam. In the case of Munich, the diversity of migrant populations reflects more the high-skilled migrants, coming for the science-driven activities in Munich. This diversity is also reflected in the fact that this cluster features post-industrial cities with only a few major industries like Rotterdam as well as typical student cities such as Heidelberg, showing resemblance to up-scale cities in GlickSchiller and Çağlar's classification. This reveals that cities can have a similar volume of diversity, yet for different reasons and probably with very different implications in terms of urban governance of migration and diversity.

Given a common image of Paris as one of the most segregated cities in Europe, one may ask why in this study it appears to be the least segregated among its cluster. The reason for it could lie in the way of measurement. While we focus on the first generation of migrants - foreign citizens (in France) - the idea of segregated neighbourhoods in this city may be largely based on the analysis of socio-economic disadvantages, race and ethnicity. However, our finding demonstrates that in Paris, unlike in other very diverse cities, i.e. Rome or Milan, nationals and non-nationals on average are more prone to live next to one another. These include both rich and poor, white and 'black' areas, pointing that in administratively 'colour-blind' France, the distribution of national and non-nationals is less uneven in the city, than it could be presumed when segregation is perceived on the basis of ethnicity.

As the cities in this cluster come closest to what is described in the literature as 'superdiverse cities', we will refer to this cluster as such. These are the cities that have been most studied in the literature on migration and cities that stand out from others in terms of size and degree of diversity. However, our clustering shows that this is just one of the clusters that have been identified, not all cities are superdiverse cities.

\section{Cluster 2: Cities with Many Migrants from Few Backgrounds (Migrant Minority Cities)}

The second cluster consists of relatively smaller cities with a considerable presence of migrant minorities. These cities have a relatively high average volume of diversity, with $18 \%$ of the population being foreign-born or of different nationalities. However, this involves far fewer different backgrounds than in cluster 1, on average, 76 different origins. This means that specific migrant minorities make up for a relatively sizeable part of the urban population. Furthermore, this cluster consists of smaller cities (average of around 270,000 inhabitants), with an about average GPD, income and unemployment levels, indicating a relatively strong economy, with an above-average percentage of population employed in the industrial sector. Interestingly, many German cities belong to this cluster, for instance, Wuppertal, Konstanz, Duisburg, Bochum, Darmstadt, Dortmund. One French city-Mulhouse - is also part of this group.

When taking a closer look at Paderborn, Giessen and Mulhouse, it becomes clear that the migration-related diversity in these cities stems much from the industrial work 
available in these cities (over $28 \%$ of the cities on average employed in industries), such as Siemens-Nixdorf in Paderborn and car factories in Mulhouse. This is also manifested in the type of migrants that have settled in these cities, which are primarily descendants of guest labourers (Turks and Polish in Germany, Moroccans and Tunisians in France). This accounts for why this city type is overrepresented in a country such as Germany with a distinct migration history of guest labourers. The economic positions of the cities, therefore, emerge as the common denominator for cities in this cluster. In comparison to cluster 1, the cities in this cluster are characterised by a lower (but still average) economic position, providing a narrower range of economic opportunities. This may have resulted in the lower migrant diversity in these cities against the background of post-industrial transformation in their respective countries.

When compared to Glick-Schiller and Caglar's typology, this cluster seems to approximate the low-scale cities, due to their narrow opportunity structures largely bound to a single type of industry. It stands out from others in particular because it combines a relatively high volume with a moderate variety of diversity (especially when compared to the superdiverse cities of cluster 1). This can be explained by the presence of sizeable migrant minorities in these cities, which represent only a number of specific backgrounds but do make up a considerable part of the population. Hence, we will refer to this cluster as 'migrant minority cities.'

\section{Cluster 3: Segregated Cities with Few Migrants From Many Backgrounds (New Diversity Cities)}

In clear contrast to migrant minority cities, the third cluster includes cities with a relatively low volume of diversity (an average of $11 \%$ migrants) but a relatively high variety of diversity (on average 76 different backgrounds). This cluster includes cities of medium size (average 408,000) with average economic indicators. These cities are larger and have a lower volume of migrant population than the 'migrant minority cities'. Yet similarly, they also seem to represent cities with a strong industrial profile (over $27 \%$ employed in industries) but able to attract the 'creative classes'. This is clearly reflected in the cities included in this cluster, with industrial cities as Osnabruck, Brescia, Eindhoven, Ingolstadt, Bamberg, with also various port cities, i.e. Nimes, Genoa, Venice, Marseille, Kiel. Additionally, this cluster does seem to come with somewhat higher levels of segregation which may be due to the concentration of migrant populations in the housing facilities provided for a lower price by universities, port and industrial companies.

However, cities in this cluster seem to come close to Glick-Schiller and Çağlar's upscale type, as they are more economically powerful than the 'migrant minority cities', and could offer more varied opportunities for economic incorporation. Moreover, their hybrid profiles bring a demand for foreign labour, hence different reasons for being diverse cities with migrants from many different backgrounds. For instance, Eindhoven is both an industrial and research-and-innovation centre. Brescia is an industrial city, with a prominent university, wine production and tourism. Bamberg and Trier are also both industrial and university city whereas Verona's economy is shaped by tourism, agriculture, transportation hub (airport) as well as industry. As in Glick-Schiller and Çağlar's up-scale cities, the cities in cluster 3 are characterised by the ongoing economic restructuring and provide a rather diverse scope of opportunity structures 
for migrants. So, the current relatively high diversity with a rather small number of migrants may increase in the near future, if the cities continue to develop and attract more migrants, which may eventually bring some of them into the league of 'superdiverse', 'top-scale' cities.

Although, when compared with superdiverse cities, these localities are clearly less diverse. Following Glick-Schiller and Çağlar's scale approach, the economic development of these cities (industrial, university-related or other) in the 5-year period that we observe may be one of the key reasons behind the relatively diverse profile of these cities. Therefore, assuming that there is a correlation between their economic development and migrant population, and their rising economic power, we will describe this cluster as 'new diversity cities'.

\section{Cluster 4: Mixed Cities with Low Diversity (Low-Migration Cities)}

The fourth cluster includes relatively small (around 200,000) cities that are also not so diverse ( $7 \%$ migrants, 60 different backgrounds on average). These cities mostly have a weaker economic profile than the first 3 clusters yet slightly better than Cluster 5 , indicated by below-average GPD, income and above-average unemployment rate. French and East German cities constitute a majority in this cluster, among which are Chemnitz, Dresden, Görlitz, Halle/Saale, Magdeburg and Brest, Lille, Lyon, Bordeaux, Toulouse. Compared to other clusters, these cities have lower levels of residential segregation (segregation index of 0.26). It seems like these cities represent what GlickSchiller and Çağlar defined as low- and down-scale cities.

Three factors explain why the cities seem to attract fewer migrants than the other clusters, and that there is no clear link with a specific migrant category despite the fact that the cluster is featuring about 60 different backgrounds per city on average. First, Glick Schiller \& Çağlar's (2009, p. 194) own description of Halle shows that some of these cities struggle to attract private capital and skilled labour and rebrand themselves to develop opportunity structures to sustain a critical mass of 'creative classes' both from their native and newcomer population. For German cities, this might be a reflection of the ongoing economic inequalities between the East and the West even 30 years after the unification. Second, considering that French cities such as Lille are also in this cluster, it may also be that some of these cities are in fact 'old' cities of migration, which have not been experiencing significant immigration for already a while, and those migrants who have arrived earlier have already naturalised and therefore are not counted in our statistical calculations as 'migrants'. Third, when taking a closer look at Metz, Angers and Weimar, it is clear that these cities are primarily important regional centres. They do have a very diverse type of economic activity, including industry (Angers, Metz) as well as tourism and services (Weimar, Angers), but with a primarily regional function.

Moreover, this cluster stands out in comparison to others for its low levels of residential segregation. This may be due to the absence of an industrial legacy of segregated labour housing and the availability of more equally affordable housing prices. Also, it is possible that residential spreading is facilitated by the relatively low numbers of migrants and, more importantly, the absence of a clear link with a specific migrant category. We, therefore, describe these cities as 'low-migration cities', as they represent urban centres that because of their regional and/or specific economic function are shaped relatively less by contemporary migration and mobility trends. 


\section{Cluster 5: Segregated Non-Diverse Cities (Non-Diverse Cities)}

Finally, the fifth cluster represents mostly mid-sized cities (average around 480,000 inhabitants) that are relatively non-diverse (2\% migrant share, an average of 36 different backgrounds) and strongly segregated (42\% of the population would need to move in order to achieve equal distribution across the city). The cities in this cluster often have a rather weak economy, characterised by low GDP and high unemployment rates (on average above 12\%). Most of these cities are located in southern ItalyCatania, Naples, Palermo, Bari and others; the German city of Passau is an outlier with a significantly better economy than the rest. In terms of diversity, these cities have low numbers of migrants of a few nationalities, concentrated in a few neighbourhoods, which explains the highest segregation levels in the cities of this cluster.

When taking a closer look at Bari, Messina and Passau, it becomes clear that although the resident population with a migration background is relatively small, the cities do take an important position in international migration flows. In fact, all three cities seem important pass-through cities for significant numbers of migrants. Bari has been a traditional point of entry for migrants from the Mediterranean, and so has Messina as a point of departure for boats to mainland Italy. Passau is located very close to the German-Austrian border and also served as an important point of entry into Germany for refugees from the former Yugoslav Republic and more recently from Syria. So, these are cities of 'transit' migration, but just not of immigration, due to limited economic opportunities for settlement.

Furthermore, especially Bari and Messina reveal the weak economic position characteristic for this cluster. Both are port cities that have been struggling to reinvent their economies, which may be one of the reasons for migrants to be primarily passing through. Their port history is also manifest in the housing situation, which is characterised by high levels of residential segregation, now also manifest in segregation along with migration background. Passau seems to be different in this regard as a city with a relatively solid economy, but possibly the passing-through character of the city also has consequences for the places where migrants settle. Passau is also a university city, but of regional importance, so it does not attract too many international students, who probably live in student accommodation.

Although these may be cities that are encountering migration, they can be described as non-diverse cities. This lack of diversity is reflected in the low levels of diversity as well as in segregation. However, we have to note here that these are rather frontier cities in relatively less developed parts of their respective countries; hence, it is even more likely that they have not been through linear industrialisation and deindustrialisation processes as we more clearly observe in other clusters. Having said this, such city profiles look close to 'down-scale cities' at least in terms of their struggle to attract capital and labour, hence the limited incorporation pathways available for the newcomers, as per Glick-Schiller and Çağlar.

\section{Discussion}

Through the qualitative analysis of median cities per cluster, we obtained a better understanding of why cities find themselves in specific clusters. The cluster analysis 
leads to five key inferences. First, the differences we identify between the first three clusters make it clear that not all cities with large migrant populations can be considered 'diverse' in the same way. Our analysis provides a nuanced reading of urban diversities in the light of the critiques of methodological localism (Brenner, 2011) as well as methodological nationalism (Glick Schiller \& Çağlar, 2009), showing that three classes of cities (e.g. 1, 3 and 4) include cities from several different countries. The fact that they are not country specific implies that there are various structural forces at play and, as highlighted in our description of clusters, they are rather produced through previous migration and urban development-related processes.

Second, to a great extent, we can explain the observed urban diversity configurations with the help of the cities' economic position and type of economy. Similar to GlickSchiller and Çağlar's 'comparative theory of locality', we found that a relatively weak economic position does seem to go together in particular with low-migration and nondiverse cities. At the same time, both new diversity and superdiverse cities have a relatively strong economic profile, in terms of GDP, household income and unemployment. Again, linking to Glick-Schiller and Çağlar's dynamic continuum of positioning, our analysis also suggests that cities may experience changes in diversity configurations over time. For instance, it seems that some of the post-industrial cities that are now included amongst the superdiverse cities, in the past would have been migrant minority cities (such as Cologne and Rotterdam). Their economic differentiation seems to have been a motor of their diversification. Also, there are some cities included in the category of low-migration cities that in the past have been important cities of migration, such as Lille. However, (a) the fact that the low-migration cities show characteristics of both low- and down-scale cities and (b) that non-diverse cities seem to be not necessarily or solely shaped by deindustrialisation processes leads to the conclusion that global economic scale alone cannot account fully for how diverse or how segregated a city is. Economics matters but is not decisive for the configuration of migrationrelated diversity.

Third, and related to the second, we observe that migration history matters as well. For instance, many cities with specific guest labour migration history are part of the cluster of 'migrant minority cities'. Superdiverse cities, on the contrary, often reveal a layering of many different forms of migration. In turn, new diversity cities seem to be the ones that, for various economic reasons, are experiencing an increase in immigration, often leading to an initial period of relative segregation. The non-diverse cities too have been less attractive for immigration for economic and political reasons that are historically shaped by the processes of state formation.

Fourth, size also does not explain everything; larger cities are not necessarily 'more diverse' than smaller cities. While cross-country comparison of large cities may offer important insights into the institutional factors that shape diversity policies (MartínezAriño et al., 2019), it might reproduce the two related fallacies of methodological nationalism that we aim to avoid here: restricting global perspective on locality to global cities and generalising from locality to nation via paradigmatic cities (Glick Schiller \& Çağlar, 2009). In fact, median population size for non-diverse cities is the second largest of all clusters; this means there are very large non-diverse cities. And at the same time, there are smaller cities with a relatively high variety of diversity, such as the new diversity cities. 


\section{Conclusion}

The aim of this article is to enhance our empirical and theoretical understanding of the diversity of urban diversities. In the context of uneven attention in migration literature to global cities or superdiverse cities, our analysis reveals a plurality of migrationrelated diversities in different cities. This contributes to a more differentiated understanding of how migration-related diversities take shape in cities.

Based on a cluster analysis of a large-n dataset of 166 European cities, we classified the cities in terms of volume, variety and spread of the migrant urban population. This revealed five different city clusters:

- Superdiverse cities - mixed cities with many migrants from many backgrounds;

- Migrant minority cities - mixed cities with many migrants from few backgrounds;

- New diversity cities - segregated cities with few migrants from many backgrounds;

- Low-migration cities - mixed cities with low diversity;

- Non-diverse cities - segregated non-diverse cities.

These clusters do not constitute ideal types but rather empirical groupings of cities that share certain similarities in terms of variety, volume and spread of diversity. In our qualitative analysis, we tried to develop a better understanding of why we see these five clusters, by looking at selected median cities per cluster. This analysis revealed that the clusters bring a complexity that cannot be captured in terms of various national models nor in terms of one specific local model; the variation of different urban diversities spreads across countries. Furthermore, the clusters cannot be fully explained neither the economic positioning nor the population size of cities, which contradicts some of the work in the context of the comparative theory of locality. Finally, we found that migration history is an important factor in shaping migration-related diversities, and this can also imply that cities may 'travel' between different clusters with time.

The variety of economic and historical reasons within the cities of the same cluster, discovered as we zoomed into a few representative cities, may be an indication of 'multiple conjunctural causation' - an idea that multiple causal paths may lead to the same outcome (De Meur et al., 2002) widely accepted in set-theoretic approaches, such as QCA (Ragin \& Rihoux, 2009). The robust testing of such initial indication is beyond the scope of this study. However, our findings provide a fruitful soil for such an analysis, in which the identified clusters of cities could serve for the definition of the logical outcome, while a number of economic, historical, geographical and political contextual factors could serve as logical conditions to be tested in conjunction.

Finally, in the context of the broader literature on the local turn in migration studies, our study sets an agenda for further research on how and why different urban diversities evolve as well as on the implications of different diversities. In order to understand the complexity of urban diversities, a more in-depth comparative research to specific clusters of cities across different countries is required. Also, in terms of governance approaches, our research calls for more research on what type of governance approaches fit with specific clusters of urban diversities. This also adds further complexity to the literature on multi-level governance; on the one hand, our findings on the diversity of urban diversities call for multi-level governance as a way to enable cities to accommodate to specific diversity configurations, and on the other hand, it calls for 
more flexible inter-governmental arrangements between central and local governments as different cities will have very different needs.

\section{Appendix}
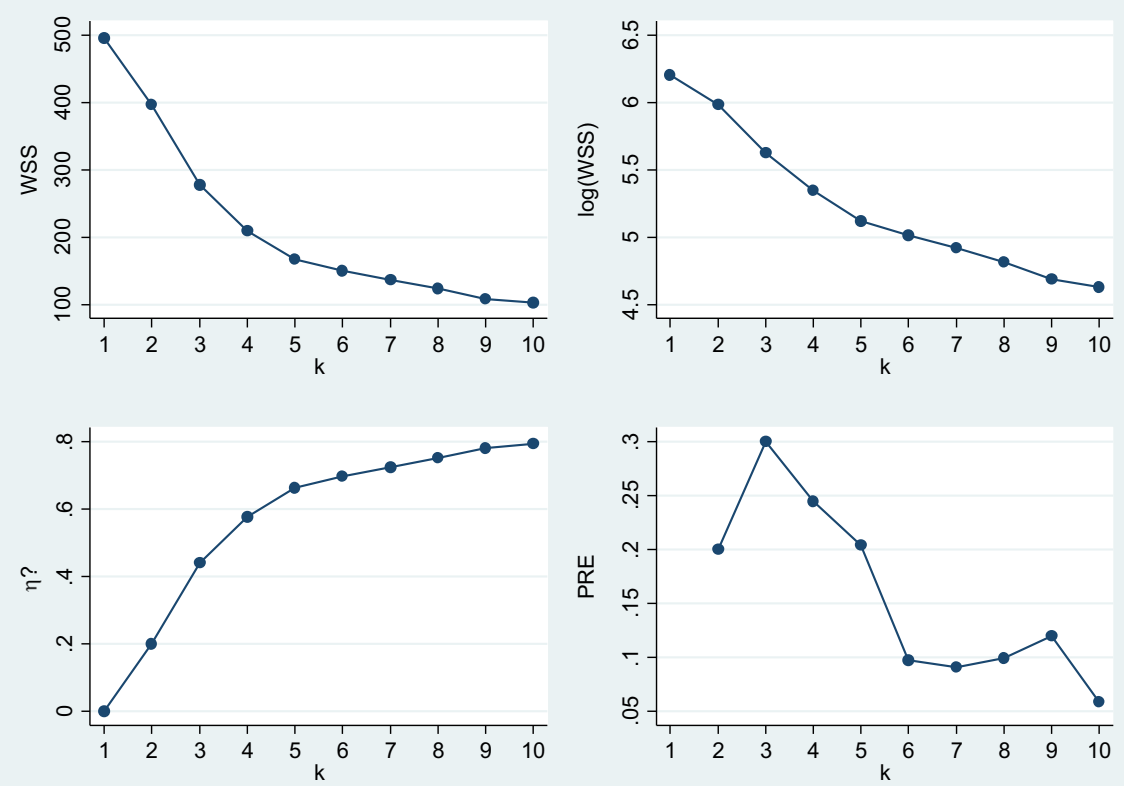

Fig. 4 Most optimal number of clusters

Open Access This article is licensed under a Creative Commons Attribution 4.0 International License, which permits use, sharing, adaptation, distribution and reproduction in any medium or format, as long as you give appropriate credit to the original author(s) and the source, provide a link to the Creative Commons licence, and indicate if changes were made. The images or other third party material in this article are included in the article's Creative Commons licence, unless indicated otherwise in a credit line to the material. If material is not included in the article's Creative Commons licence and your intended use is not permitted by statutory regulation or exceeds the permitted use, you will need to obtain permission directly from the copyright holder. To view a copy of this licence, visit http://creativecommons.org/licenses/by/4.0/.

\section{References}

Alessandrini, A., Natale, F., Sermi, F., \& Vespe, M. (2017). High resolution map of migrants in the EU. EUR, Scientific and technical research series: Vol. 28770. Luxembourg: Publications Office.

Arbaci, S., \& Malheiros, J. (2010). De-segregation, peripheralisation and the social exclusion of immigrants:

Southern European Cities in the 1990s. Journal of Ethnic and Migration Studies, 36(2), 227-255.

Bailey, K. (1994). Typologies and taxonomies. SAGE Publications, Inc.. 
Bauder, H., \& Gonzalez, D. (2018). Municipal responses to 'illegality': Urban sanctuary across national contexts. Social Inclusion, 6(1), 124-134.

Baumgärtel, M., Oomen, B., Durmus, E., Sabchev, T. \& Miellet, S. (2019). Strategies of divergence: Local authorities, law and discretionary spaces in migration governance. Paper Presented at the $16^{\text {th }}$ IMISCOE Annual Conference, June 27. Malmö.

Body-Gendrot, S., \& Mariniello, M. (2000). Minorities in European cities. Palgrave Macmillan.

Bolt, G., Özüekren, A. S., \& Phillips, D. (2010). Linking integration and residential segregation. Journal of Ethnic and Migration Studies, 36(2), 169-186.

Borsdorf, A., Hildalgo, R., \& Vidal-Koppmann, S. (2016). Social segregation and gated communities in Santiago de Chile and Buenos Aires. A comparison. Habitat International, 54, 18-27.

Bowen, P., \& Barak, K. (2014). The integration matrix reloaded: From ethnic fixations to established versus outsiders dynamics in the Netherlands. Journal of Ethnic and Migration Studies, 40(9), 1354-1374. https://doi.org/10.1080/1369183X.2013.847783.

Brenner, N. (2011). The urban question and the scale question: Some conceptual clarifications. In N. Glick Schiller \& A. Çağlar (Eds.), Locating migration: Rescaling cities and migrants (pp. 23-41). Cornell University Press.

Çağlar, A., \& Glick-Schiller, A. (2018). Migrants and city-making: Dispossession, displacement, and urban regeneration. Duke University Press.

Caponio, T., \& Borkert, M. (2010). The local dimension of migration policymaking. Amsterdam University Press.

Collier, D., Laporte, J., \& Seawright, J. (2008). Chapter 7. Typologies: Forming concepts and creating categorical variables. In J. M. Box-Steffensmeier, H. E. Brady, \& D. Collier (Eds.), The Oxford handbooks of political science. The Oxford handbook of political methodology. Oxford University Press.

Crul, M. (2016). Super-diversity vs. assimilation: How complex diversity in majority-minority cities challenges the assumptions of assimilation. Journal of Ethnic and Migration Studies, 42(1), 54-68.

De Graauw, E., \& Vermeulen, F. (2016). Cities and the politics of immigrant integration: A comparison of Berlin, Amsterdam, New York City, and San Francisco. Journal of Ethnic and Migration Studies, 42(6), 989-1012.

De Meur, G., Rihoux, B., \& Yamasaki, S. (2002). L'analyse quali-quantitative comparée (AQQC-QCA): approche, techniques et applications en sciences humaines.

Dekker, R, Emilsson, H, Krieger, B. \& Scholten, P.W.A. (2015). A local dimension of integration policies? A comparative study of Berlin, Malmö and Rotterdam. International Migration Review, 1-26, doi:https:// doi.org/10.1111/imre.12133

Emilsson, H. (2015). A national turn of local integration policy: Multi-level governance dynamics in Denmark and Sweden. Comparative Migration Studies, 3(7), 1-16.

Ferreira, F. (2010). Preferences for Hispanic neighborhoods. In Neighborhood and life chances: How place matters in modern America (pp. 257-270). Real Estate Department, Wharton School, University of Pennsylvania, United States: University of Pennsylvania Press.

Foner, N., Rath, J., Duyvendak, J. W., \& van Reekum, R. (Eds.) (2014). New York and Amsterdam: Immigration and the new urban landscape. New York University Press.

García, M. A. H., \& Moreno, R. M. (2011). Neighborhood models and logical location of the immigrant population. The case of the city of Seville. Scripta Nova, 15.

Glick Schiller, N., \& Çağlar, A. (2009). Towards a comparative theory of locality in migration studies: Migrant incorporation and city scale. Journal of Ethnic and Migration Studies, 35(2), 177-202.

Glorius, B. (2017). The challenge of diversity in rural regions: Refugee reception in 559 the German Federal State of Saxony. Hungarian Geographical. Bulletin, 66(2), 560 113-560 128.

Grzegorczyk, A. (2012). Socio-spatial diversity of Marseille at the turn of the 21st century. Bulletin of Geography, 17, 45-55.

Grzymala-Kazlowska, A., \& Phillimore, J. (2018). Introduction: Rethinking integration. New perspectives on adaptation and settlement in the era of super-diversity. Journal of Ethnic and Migration Studies, 44(2), $179-196$.

Hahn, H. P. (2010). Urban life-worlds in motion: In Africa and beyond. Africa Spectrum, 45(3), 115-129.

Ikizoglu-Erensu, A., \& Kaşl1, Z. (2016). A tale of two cities: Multiple practices of bordering and degrees of 'transit' in and through Turkey. Journal of Refugee Studies, 29(4), 528-548.

Lacroix, T., \& Desille, A. (Eds.). (2018). International migrations and local governance. Migration, Diasporas and Citizenship. Palgrave Macmillan.

Leitner, H. (2012). Spaces of encounters: Immigration, race, class, and the politics of belonging in small-town America. Annals of the Association of American 573 Geographers, 102(4), 828-846. 
Makles, A. (2012). Stata tip 110: How to get the optimal k-means cluster solution. The Stata Journal, 12(2), 347-351.

MarketLine (2019). City profiles. Retrieved December 02, 2019, from https://advantage-marketline-com.eur. idm.oclc.org/CityAnalysis.

Martínez-Ariño, J., Moutselos, M., Schönwälder, K., Jacobs, C., Schiller, M., \& Tandé, A. (2019). Why do some cities adopt more diversity policies than others? A study in France and Germany. Comparative European Politics, 17(5), 651-672.

Massey, D. S., \& Denton, N. (2018). American apartheid: Segregation and the making of the underclass. In D. Grusky \& J. Hill (Eds.), Inequality in the $21^{\text {st }}$ Century. Routledge.

Meissner, F., \& Vertovec, S. (2015). Comparing super-diversity. Ethnic and Racial Studies, 38(4), 541-555.

Mepschen, P. (2019). A discourse of displacement: super-diversity, urban citizenship, and the politics of autochthony in Amsterdam. Ethnic and Racial Studies, 42(1), 71-88.

Musterd, S., \& van Kempen, R. (2009). Segregation and housing of minority ethnic groups in Western European cities. Tijdschrift voor Economische en Sociale Geografie, 100(4), 559-566.

OECD (2012). List of urban areas by country. Retrieved April 01, 2020, from http:/www.oecd.org/cfe/ regional-policy/all.pdf.

Phillimore, J. (2015). Delivering maternity services in an era of superdiversity: The challenges of novelty and newness. Ethnic and Racial Studies, 38(4), 568-582.

Ragin, C. C., \& Rihoux, B. (2009). Configurational comparative methods: Qualitative comparative analysis (QCA) and related techniques / edited by Benoît Rihoux, Charles C. Ragin. Applied social research methods series: Vol. 51. London: SAGE.

Salzbrunn, M. (2014). How diverse is Cologne carnival? How migrants appropriate popular art spaces. Identities, 21(1), 92-106.

Sassen, S. (2001). In N. J. Princeton (Ed.), The global city: New York, London, Tokyo (2nd ed.). Princeton University Press.

Schiller, M. (2016). European cities, municipal organizations and diversity: The new politics of difference. Palgrave Macmillan.

van Breugel, I. (2020). Towards a typology of local migration diversity policies. Comparative Migration Studies, 8(1), 1-16.

van Gent, W., \& Musterd, S. (2016). Class, migrants, and the European city: Spatial impacts of structural changes in early twenty-first century Amsterdam. Journal of Ethnic and Migration Studies, 42(6), 893912.

van Oudenhoven, J. P., \& Ward, C. (2013). Fading majority cultures: The implications of transnationalism and demographic changes for immigrant acculturation. Journal of Community and Applied Social Psychology, 23(2), 81-97.

Vertovec, S. (2007). Super-diversity and its implications. Ethnic and Racial Studies, 30(6), 1024-1054.

Ward, K. (2010). Towards a relational comparative approach to the study of cities. Progress in Human Geography, 34(4), 471-487.

Weber, H. (2015). More immigrants, more xenophobia? A review of the current state of research and an attempt to explain recent developments in Germany. Berliner Journal für Soziologie, 25(4), 397-428.

Wessendorf, S. (2016). Settling in a super-diverse context: Recent migrants' experiences of conviviality. Journal of Intercultural Studies, 37(5), 449-463.

Wise, A. (2011). 'Foreign' signs and multicultural belongings on a diverse shopping street. Built Environment, 37(2), 139-154.

Zapata-Barrero, R., Caponio, T., \& Scholten, P. (2017). Theorizing the 'local turn' in a multi-level governance framework of analysis: A case study in immigrant policies. International Review of Administrative Sciences, 83(2), 241-246.

Publisher's Note Springer Nature remains neutral with regard to jurisdictional claims in published maps and institutional affiliations. 